Note

\section{Effect of Strain Difference on Lipid Metabolism in Rats after an Acute Ethanol Administration}

\author{
Satoshi Mochizuki and Akira Yoshida* \\ Faculty of Education, Oita University, \\ Oita $870-11$, Japan \\ * Laboratory of Nutritional Biochemistry, \\ Department of Agricultural Chemistry, \\ Nagoya University, \\ Nagoya 464-01, Japan \\ Received May 16, 1991
}

It is well known that the administration of an acutely large dose of ethanol to rats induces an accumulation of lipid in the liver. ${ }^{1)}$ We have investigated the preventive effect of some dietary components on fatty liver by using a model of the fatty liver induced by acute ethanol administration. We often observed no or only a slight lipid accumulation in the liver, even when we administered ethanol by the method reported in the previous paper. ${ }^{1)}$ We supposed that one of the reasons might be due to the breeder and/or strain differences in the rats.

Male Sprague-Dawley (SD) rats at 5 weeks of age were obtained from Charles River Japan (Kanagawa), Nihon Clea (Tokyo), Nihon SLC (Shizuoka), and Seiwa Laboratory Animals (Fukuoka), respectively. They were fed on a laboratory diet (MF; Oriental Yeast Co., Tokyo) for a week and divided into control and ethanol groups of six animals each. Five $\mathrm{g} / \mathrm{kg}$ of an ethanol solution $(25 \mathrm{w} / \mathrm{v} \%)$ was given to the rats in the ethanol group, and isocaloric glucose solutions were given to the control rats by stomach tube. The diet was withdrawn after administration and they were decapitated after $16 \mathrm{hr}$. The liver was removed from each and the total lipid was measured gravimetrically after extracting and purifying according to the method of Folch et al. ${ }^{2)}$ Significant differences were assessed by Student's $t$-test. ${ }^{3)}$

The results are shown in Table I. No significant lipid accumulation in the liver from acute ethanol administration was observed in the SD rats from each breeder. Next, we carried out the same experiment with three strains of rats. Male 5 week-old Donryu, SD and Wistar rats (Nihon SLC Co., Shizuoka) were used. The same experimental procedure was run. The liver total lipid was measured, and liver triglyceride (TG), cholesterol (CHL) and phospholipid (PL) were each determined by using commercially available kits (Determinar, Kyowa Medex Co., Tokyo). Serum TG, CHL, PL and non-esterified fatty acid (NEFA) were also determined by the same kits. Liver total lipid was significantly increased in the Donryu rats. In the SD rats, the increase was significant but slight. No increase was found in the Wistar rats. In the Donryu rats, the increases in the $\mathrm{TG}$ and $\mathrm{CHL}$ fractions were significant, while in the SD rats, $\mathrm{TG}$ was increased significantly. Conversely, in the Wistar rats, TG and PL were significantly decreased (Table II). Serum CHL and

Table I. Effects of Acute Ethanol Administration on Liver Total Lipid in Sprague-Dawley RATS FROM 4 BREEDERS ${ }^{a}$

\begin{tabular}{lcc}
\hline \multirow{2}{*}{ Breeder } & \multicolumn{2}{c}{ Group } \\
\cline { 2 - 3 } & Control & Ethanol \\
& \multicolumn{2}{c}{$\mathrm{mg} / \mathrm{g}$ of liver } \\
Charles River & $65.2 \pm 7.8$ & $77.6 \pm 2.3$ \\
Nihon Clea & $56.7 \pm 2.0$ & $59.9 \pm 3.4$ \\
Nihon SLC & $59.1 \pm 1.3$ & $61.4 \pm 4.1$ \\
Seiwa & $57.8 \pm 4.4$ & $67.9 \pm 4.4$ \\
\hline
\end{tabular}

a Values are means $\pm \operatorname{SEM}(n=6)$.

Table II. Effects of Acute Ethanol Administration on Liver Lipids in 3 Strains of Rats ${ }^{a}$

\begin{tabular}{|c|c|c|c|c|c|c|}
\hline \multirow{2}{*}{ Group } & \multicolumn{2}{|c|}{ Donryu } & \multicolumn{2}{|c|}{ Sprague-Dawley } & \multicolumn{2}{|c|}{ Wistar } \\
\hline & Control & Ethanol & Control & Ethanol & Control & Ethanol \\
\hline & \multicolumn{2}{|c|}{$\mathrm{mg} / \mathrm{g}$ of liver } & \multicolumn{2}{|c|}{$\mathrm{mg} / \mathrm{g}$ of liver } & \multicolumn{2}{|c|}{$\mathrm{mg} / \mathrm{g}$ of liver } \\
\hline Total lipid & $70.6 \pm 2.9$ & $93.6 \pm 3.1 * *$ & $59.4 \pm 2.6$ & $64.1 \pm 1.4^{*}$ & $52.1 \pm 0.8$ & $47.6 \pm 3.5$ \\
\hline $\mathrm{TG}$ & $13.6 \pm 1.8$ & $29.5 \pm 3.0^{*}$ & $6.6 \pm 1.3$ & $10.1 \pm 0.8^{*}$ & $9.9 \pm 0.9$ & $7.6 \pm 1.0^{*}$ \\
\hline $\mathrm{CHL}$ & $3.88 \pm 0.03$ & $4.16 \pm 0.07 * *$ & $3.90 \pm 0.18$ & $3.64 \pm 0.07$ & $3.22 \pm 0.07$ & $3.26 \pm 0.06$ \\
\hline $\mathrm{PL}$ & $22.3 \pm 0.4$ & $22.8 \pm 0.2$ & $23.2 \pm 0.8$ & $22.0 \pm 0.3$ & $21.2 \pm 0.4$ & $19.7 \pm 0.4^{* *}$ \\
\hline
\end{tabular}

a Values are means $\pm \operatorname{SEM}(n=6)$.

Abbreviations: TG, triglyceride; CHL, cholesterol; PL, phospholipid.

* Significantly different from each of the controls $(p<0.05)$.

** Significantly different from each of the controls $(p<0.01)$. 
Table III. Effects of Acute Ethanol Administration on Serum Lipids in 3 Strains of Rats ${ }^{a}$

\begin{tabular}{|c|c|c|c|c|c|c|}
\hline \multirow{2}{*}{ Group } & \multicolumn{2}{|c|}{ Donryu } & \multicolumn{2}{|c|}{ Sprague-Dawley } & \multicolumn{2}{|c|}{ Wistar } \\
\hline & Control & Ethanol & Control & Ethanol & Control & Ethanol \\
\hline $\begin{array}{c}\text { CHL } \\
(\mathrm{mg} / 100 \mathrm{ml})\end{array}$ & $56.6 \pm 2.9$ & $71.0 \pm 3.7 *$ & $54.2 \pm 2.9$ & $65.6 \pm 2.8^{*}$ & $54.3 \pm 1.8$ & $78.2 \pm 2.4^{* *}$ \\
\hline $\begin{array}{c}\mathrm{PL} \\
(\mathrm{mg} / 100 \mathrm{ml})\end{array}$ & $100 \pm 7$ & $132 \pm 4^{* *}$ & $100 \pm 3$ & $131 \pm 5^{* *}$ & $103 \pm 2$ & $133 \pm 2 * *$ \\
\hline $\begin{array}{l}\text { NEFA } \\
(\mathrm{mEq} / \mathrm{l})\end{array}$ & $0.76 \pm 0.04$ & $0.98 \pm 0.04^{* *}$ & $0.84 \pm 0.02$ & $0.98 \pm 0.04^{* *}$ & $0.91 \pm 0.08$ & $0.77 \pm 0.03$ \\
\hline $\begin{array}{c}\mathrm{TG} \\
(\mathrm{mg} / 100 \mathrm{ml})\end{array}$ & $40.2 \pm 4.0$ & $69.6 \pm 4.9^{* *}$ & $48.6 \pm 3.3$ & $50.6 \pm 4.6$ & $50.0 \pm 4.7$ & $40.6 \pm 5.4$ \\
\hline
\end{tabular}

a Values are means $\pm \operatorname{SEM}(n=6)$.

Abbreviations: CHL, cholesterol; PL, phospholipid; NEFA, non-esterified fatty acid; TG, triglyceride.

* Significantly different from each of the controls $(p<0.05)$.

** Significantly different from each of the controls $(p<0.01)$.

PL were elevated in the ethanol groups of all strains, but NEFA was increased only in the Donryu and SD strains. TG was increased in only the Donryu rats (Table III).

The mobilization of NEFA from adipose tissue through the secretion of catecholamine is guessed as one of the possible mechanisms for inducing fatty liver by acute ethanol administration. ${ }^{4)}$ A possible reason for no accumulation of lipid in the liver of the Wistar rats may be that there was no mobilization of fatty acid from adipose tissue, because the serum NEFA was not elevated. Hyperlipemia occurring $10-16 \mathrm{hr}$ after administering an acutely large dose of ethanol to rats has been reported by some workers, ${ }^{5,6)}$ but not by others. ${ }^{7,8)}$ Diluzio and Poggi ${ }^{57}$ described that this hyperlipemia was enhanced if lipid was given simultaneously with ethanol. Our results show that hyperlipemia occurred in the Donryu strain, but not in the other strains of rats, irrespective of simultaneous administration of lipid.

Not only acute administration but chronic feeding of ethanol is known to induce fatty liver. ${ }^{9,10}$ We have found, however, no lipid accumulation in the liver from the chronic experiment, ${ }^{11}$ ) using male Wistar rats. From the present experiment, lipid metabolism in Wistar rats is thought to be little effected by the administration of ethanol. In any future study on the chronic effects of ethanol on lipid metabolism, selecting the strain of rats is considered to be significant.

Acknowledgment. This study was supported in part by a Grant-in-Aid for Scientific Research (No. 02780061) from the Ministry of Education, Science and Culture of Japan.

\section{References}

1) S. Mallov and J. L. Bloch, Am. J. Physiol., 184, 29 (1956).

2) J. Folch, M. Lees and G. H. Sloane-Stanley, J. Biol. Chem., 226, 497 (1957).

3) G. W. Snedecor and W. G. Cochran, Statistical Methods, 6th Ed., The Iowa State University Press, Ames, IA, 1967.

4) H. Kalant, R. D. Hawkins and C. Czaja, Am. J. Physiol., 204, 849 (1963).

5) N. R. DiLuzio and M. Poggi, Life Sci., 10, 751 (1963).

6) S. P. Mistilis and R. K. Ockner, J. Lab. Clin. Med., 80, 34 (1972).

7) E. E. Elko, W. R. Wooles and N. R. Diluzio, Am. J. Physiol., 201, 923 (1961).

8) A. Seakins and D. S. Robinson, Biochem. J., 92, 308 (1964).

9) L. M. DeCarli and C. S. Lieber, J. Nutr., 91, 331 (1967).

10) E. Baraona and C. S. Lieber, J. Lipid Res., 20, 289 (1979).

11) S. Mochizuki and A. Yoshida, J. Nutr. Sci. Vitaminol., 35, 431 (1989). 